\title{
Aspectos linguísticos e educação ambiental na aprendizagem infantil
}

\author{
Graziela Cristina Montanhim ${ }^{1}$ \\ Mônica Filomena Caron ${ }^{2}$ \\ Heloísa Chalmers Sisla Cinquetti ${ }^{3}$
}

Resumo: Este estudo tem por objetivo discutir a linguagem de crianças de 5 a 6 anos apresentada em mediações sobre a temática ambiental, sobre conceitos e atitudes relativos ao tema "água", a fim de contribuir para a compreensão dessa linguagem e suas consequências para as propostas de ensino e mediações de educadores que atuam com essa faixa etária. O estudo é fruto de uma pesquisa cujo objetivo foi analisar a peculiaridade da expressão linguística das crianças. Apresentamos as concepções adotadas de educação ambiental, do processo de ensino e aprendizagem e do desenvolvimento/funcionamento da linguagem na infância. Os procedimentos metodológicos aos quais recorremos foram: pesquisa com intervenção e Paradigma Indiciário. Nas análises destacaram-se as discussões sobre o papel da linguagem nas mediações sobre a água, em especial a proximidade ou distanciamento entre os conceitos cotidianos e científicos, a compreensão de metáforas e as argumentações relativas à lavagem de calçadas.

Palavras-chave: Linguagem. Educação infantil. Educação ambiental. Pesquisa-ação.

\section{Linguistic aspacts and environmental education in childhood learning}

\begin{abstract}
This study sought to discuss the language provided by 5 and 6-year-old children in mediations about concepts and attitudes related to water, intending to contribute to the understanding of their language and its consequences to teaching procedures and mediations in early education. The study is the result of a research that aimed to analyze the peculiarity of children's linguistic expression. We present the adopted theoretical framework on environmental education, on the teaching and learning process, and on language development in childhood. The methodologies adopted were action research and evidence-based paradigm. The analysis points out discussions about the role of language in mediations about water, in particular how close or distant are scientific and everyday concepts, the understanding of metaphors and reasoning related to sidewalk washing.
\end{abstract}

Keywords: Language. Early childhood education. Environmental education. Action research.

1 Graduanda em Licenciatura Plena em Ciências Biológicas - Ufscar; gramontanhim@yahoo.com.br

2 Professora da Ufscar - Campus de Sorocaba monicacaron@yahoo.com.br

3 Professora da Ufscar - Campus de São Carlos heloisasis@ufscar.br 


\section{Introdução: antecedentes}

A ideia do desenvolvimento da pesquisa surgiu a partir de um fato ocorrido em setembro de 2007, numa aula dada pela primeira autora deste artigo (doravante denominada pesquisadora discente).

As disciplinas Prática e Pesquisa em Ensino de Ciências e Biologia 1 e Didática propuseram aos discentes de graduação do segundo semestre do curso de Licenciatura em Ciências Biológicas de uma universidade pública do interior de São Paulo que realizassem uma intervenção em sala de aula de uma instituição pública de ensino. Essa intervenção foi realizada pela pesquisadora discente numa escola de ensino fundamental e médio, em dupla com outra discente do referido curso. $\mathrm{Na}$ ocasião, deu-se sequência ao planejamento que a professora responsável pela turma tinha em mãos. Tratava-se de uma $5^{a}$ série com, aproximadamente, 30 alunos e o assunto tratado era "o ciclo da água". Em geral, os alunos foram participativos e fizeram várias perguntas, às quais poucas vezes a dupla de discentes não apresentou uma resposta. Eram indagações criativas e bem formuladas. Em particular, dois comentários de alunos intrigaram a pesquisadora discente.

Uma das questões tratava sobre "as pessoas que têm água no quintal"4. A resposta dada afirmava que isso era possível através da escavação de um poço artesiano. $\mathrm{O}$ aluno então afirmou que seria bom ter um poço em seu quintal. Foi dito que esses poços só poderiam ser construídos em locais apropriados e por pessoas especializadas (profissionais), como engenheiros agrônomos. "O que é isso? Falou difícil, doninha", foi o comentário feito pelo aluno, que levou a crer que desconhecia o termo "engenheiros agrônomos" e que o considerava difícil.

Ao final da intervenção, as discentes explicaram a atividade que deveria ser realizada. O enunciado da avaliação era: "Esquematize o ciclo da água". Uma aluna reagiu dizendo: "Traduz, doninha, traduz! Falou difícil". A maioria dos outros alunos demonstrou a mesma reação, indicando que não sabia o que significava "esquematize".

Foi por meio de situações como as acima relatadas que se percebeu o quanto a linguagem utilizada pelos educadores influencia e é determinante para que ocorra efetivamente a aprendizagem. Essas situações despertaram o interesse da pesquisadora discente e a ideia de realizar este projeto, que analisa a linguagem em mediações de educação ambiental (doravante denominada EA), considerando que cada faixa etária e grupo social dispõe de uma "variedade" linguística peculiar/própria e faz usos particulares da linguagem, que exigem que, na interlocução, se pense na forma mais apropriada para se atingir o público para o qual se dirige.

${ }^{4}$ É importante esclarecer que o sentido dado à expressão "água no quintal” referia-se ao fato de que há pessoas que têm poços em suas casas, o que as exime de pagar pelo produto, além de ser cômodo. 
A partir dessa preocupação inicial com a linguagem de educadores e de educandos é que traçamos o objetivo da pesquisa, qual seja, analisar o papel da linguagem em mediações sobre a temática ambiental, com foco nas relações entre a linguagem (principalmente na modalidade oral) empregada por adultos e crianças e as possibilidades de compreensão e aprendizagem dos conteúdos de EA, considerando as peculiaridades da expressão linguística da faixa etária escolhida (5 a 6 anos). A hipótese do trabalho era que a linguagem utilizada (seja ela visual, verbal, escrita ou audiovisual) em qualquer ato de ensinoaprendizagem influencia, determina, possibilita ou não a compreensão e a aprendizagem dos educandos dos conceitos de EA.

O artigo apresenta inicialmente os apoios teóricos em EA, a concepção de linguagem adotada, assim como uma breve caracterização da linguagem infantil. Prossegue com a apresentação dos referenciais metodológicos e a descrição da intervenção. Na seção Resultados e Discussão são analisados os dados com base nos referenciais adotados. A última seção constitui uma síntese das principais análises e indica algumas questões e reflexões delas decorrentes.

\section{Bases teóricas}

\section{Educação ambiental}

Consideramos importante explicitar o entendimento de EA que apoiou esta pesquisa, o que fazemos a seguir. Carvalho (2004) distingue dois grandes grupos entre as diversas tendências da EA: o da orientação comportamentalista e o que denomina orientações crítico-reflexivas. A orientação comportamentalista, segundo a autora, é ainda comum em discursos e ações de EA. Essa tendência tem como ponto de partida a mudança de comportamento, enfatizando o que deve ser feito e qual é a forma correta de fazer. Representa, assim, uma vertente normativa, estabelecendo ações e procedimentos que se julgam corretos (por quem ensina). Segundo essa autora, esse é um tipo de EA que ensina regras que devem ser obedecidas (como, por exemplo, "devemos fechar a torneira ao escovar os dentes", "é preciso reciclar", "não se deve lavar a calçada com a mangueira"). Carvalho (2004) questiona se é esse tipo de educação o que queremos e o que seria mais efetivo para um projeto ambiental e social que pretende transformações que colocam as pessoas como protagonistas da ação. Os limites da EA de orientação comportamentalista se apresentam quando presenciamos educandos que, a despeito de "terem sido educados", continuam, em outros contextos, perpetuando atitudes que não são movidas pela reflexão e preocupação com as questões ambientais.

Como alternativa à orientação comportamentalista, os educadores buscam exercer e teorizar sobre uma EA que volte a sua atenção para a provocação, a indagação, a compreensão dos fenômenos ambientais, com a consequente mobilização para as mudanças que os diferentes grupos sociais julgam importantes, mudanças negociadas e debatidas em vez de ditadas de um grupo a outro, que as repete. Uma EA que se volte para o que Carvalho (2004) chama de 
uma formação de sujeitos ecológicos, que atribua sentido às experiências vividas e que avance para considerar o sujeito não só em sua racionalidade mas em outras dimensões, que se interpõem entre a intenção e o gesto, muitas vezes não conscientes, contraditórias, amparadas por determinantes afetivos, relacionais e culturais. Para essa autora, diferentes vertentes da EA, como a teoria da aprendizagem significativa, os estudos culturais, a pedagogia crítica e as abordagens construtivistas, podem ser agrupadas e se contrapor à comportamentalista, pois apresentam convergências:

[...] a concepção de educação como processo permanente, aberto e formativo, no qual a relação de ensino/aprendizagem envolve processos cognitivos e socioculturais de atribuição de significados [...] sendo o aprender entendido como ato cultural, sempre contextualizado, inserido em um universo simbólico dos sentidos sociais, individuais e coletivos (CARVALHO, 2004, p. 185).

Esta pesquisa teve como base as concepções de EA do grande grupo das perspectivas crítico-reflexivas, que ora apresentamos. Pensamos, em acordo com os princípios dos teóricos sociointeracionistas, que o sujeito que aprende é (cognitivamente) ativo na aquisição de conhecimento. Seus conhecimentos prévios e preconceitos a respeito do que está aprendendo devem ser considerados e conectados às novas informações que estão sendo apresentadas. Cabe a quem ensina levantar dados sobre os educandos buscando identificar os conhecimentos que eles já possuem e quais as relações existentes na literatura entre os conceitos cotidianos que as crianças têm estruturados e os conceitos científicos articulados pelos especialistas. Um conceito importante quando consideramos as relações entre os conceitos cotidianos e científicos é o de zona de desenvolvimento proximal (ZDP), concebido por Vygotsky (1988) e que sugere que há uma distância entre o que as crianças sabem em determinada faixa etária e o que poderiam saber caso fossem auxiliadas na realização de tarefas por adultos ou crianças mais velhas. Segundo Vygotsky (1987), esse processo de formação de conceitos percorre um caminho que parte de formulações marcadas pelo sincretismo, próprio da lógica infantil, impregnada das suas percepções imediatas e subjetivas, passa pelo pensamento, em que já se evidenciam alguns elementos que aglutinam ideias em torno de um pseudoconceito, e alcança uma terceira fase, a da verdadeira formação de conceitos, caracterizada por possibilidades maiores de abstração e generalização. Tem destaque nesse processo o papel da palavra, representado pela linguagem que o adulto apresenta à criança, pois, na medida em que propõe e nomeia os conceitos, desafia a criança a tentar compreender o conceito e empregá-lo em situações diversificadas.

Nessa abordagem o papel do professor ganha destaque. Alguns educadores têm criticado os efeitos de uma abordagem na qual o papel do professor é meramente criar o ambiente, apresentar os materiais, fazer perguntas e aceitar sem julgamento respostas incorretas. Esses educadores argumentam que uma 
ação pedagógica baseada em tais características leva a um estado de "laissezfaire", no qual a aprendizagem pode ou não ocorrer. Recorrem, entre outros, aos estudos de Vygotsky, para quem o ensino tem um papel fundamental no desenvolvimento dos conceitos científicos, estando mesmo à frente destes. Nessa abordagem, o professor é o interlocutor privilegiado, aquele que dirige, sabe ou busca saber em que estágio do desenvolvimento dos conceitos estão seus alunos, procura ter clareza e propõe desafios baseados nos próximos conceitos a serem construídos e os objetivos a serem alcançados. É uma presença diretiva, de alguém que orienta os alunos nos trabalhos em grupo fazendo perguntas individualmente e para o grupo, trocando pontos de vista, conduzindo atividades de classe, organizando, elogiando e criticando.

Cremos também ser preciso resgatar a importância dos conteúdos na aprendizagem escolar. Entendemos que muitas propostas pedagógicas vêm relegando os conteúdos a um segundo plano, o que é ainda mais comum na educação infantil. Consideram que o processo de aprender é mais importante do que os conteúdos de fato aprendidos e que se aprende mais efetivamente quando o aluno descobre sozinho. Sem deixar de considerar a trajetória do estudante, pensamos que não é possível abrir mão de resultados. Processo e produto são importantes. Nesse sentido, concordamos com os educadores que têm sugerido que é fundamental resgatar a importância da aprendizagem dos conteúdos sistematizados como forma de oferecer oportunidades democráticas para que as crianças tenham uma formação que lhes propicie o exercício da cidadania de forma crítica e transformadora. A concepção de conteúdos aqui explicitada não se reduz ao campo conceitual, incluindo ainda as dimensões procedimental e atitudinal, como sugere Zabala (2008). Cabe esclarecer também que a defesa do resgate dos conteúdos está em acordo com o que propõe o Referencial Curricular Nacional para Educação Infantil (BRASIL, 1998), que em seu volume 3 recomenda que os fenômenos naturais sejam abordados no eixo de trabalho Natureza e Sociedade e explicita que um dos dois conteúdos a serem trabalhados no bloco Fenômenos da Natureza seja o estabelecimento de relações entre os fenômenos naturais de diferentes regiões e os grupos sociais que nelas vivem.

Nossa concepção de EA parte do entendimento de que são três as dimensões nas quais devem se apoiar ações educativas ou pesquisas, como proposto por Carvalho et al. (1996): conhecimentos, valores (éticos e estéticos) e participação política. Tais dimensões vêm sendo apresentadas, com diferentes formas de organização, por autores da área. A primeira delas, dos conhecimentos, é a primeira em que pensamos e muitas práticas de EA, aquelas menos fundamentadas, restringem-se a ela. Diz respeito a quais conhecimentos devem ser ensinados e aprendidos e que ênfases devem ser dadas a quais conteúdos da temática ambiental. Toma como parâmetro as informações disponíveis nos vários campos científicos ou não, como na Filosofia e nos saberes populares. Dirige a sua atenção ainda para as concepções da relação entre ser humano e natureza e do fenômeno educativo.

Muitos estudos e documentos internacionais indicam, entretanto, que não basta tratar dos aspectos informativos nas práticas pedagógicas, pois, se os 
conhecimentos não forem acompanhados de questionamentos e mudança de valores éticos e estéticos, as práticas e pesquisas serão menos consequentes, críticas e efetivas. Dessa constatação emerge a segunda dimensão, dos valores éticos e estéticos, que se volta para a discussão tanto das compreensões que se têm desses valores nas ações e pesquisas em EA quanto dos procedimentos didáticos. Em nossa compreensão, procedimentos pautados pelo diálogo, pela provocação e discussão de controvérsias, entre outros, devem ser privilegiados para que as práticas se distanciem de abordagens normativas e prescritivas, tão frequentes nos materiais didáticos (CARVALHO et al., 1996) e mencionadas ao nos referirmos à orientação comportamentalista, criticada por Carvalho (2004).

A última dimensão é a da participação política, destacada por vários autores, como Carvalho et al. (1996), Carvalho (2004) e Reigota (1999), que vêm indicando que não basta o questionamento dos educadores para a atuação em EA, pois os trabalhos requerem um posicionamento político, assim como ações individuais e coletivas, que possibilitem o exercício da cidadania, especialmente em reflexões e ações voltadas para formas democráticas de influenciar e propor políticas.

Ainda são poucos os estudos de EA voltados para a faixa etária da educação infantil, conforme indicam Kawasaki et al. (2009). Segundo Ruffino (2003), ainda faltam apoios teóricos específicos para os trabalhos de EA na educação infantil, o que leva a práticas ultrapassadas ou limitadas, como aquelas voltadas para a reciclagem, embora, segundo ela, tais propostas não deixem de aproximar as pessoas da temática.

\section{Concepção de linguagem e características da linguagem infantil}

Indicaremos nesta seção a concepção de linguagem que pautou a intervenção e as análises, assim como algumas das características da linguagem de crianças.

Admitimos que a linguagem é uma atividade constitutiva (FRANCHI, 1977), marcada pela história e pelas interações sociais. Nessa perspectiva, importa a dinâmica do trabalho linguístico, ininterrupto, já que:

[...] não há nada imanente na linguagem, salvo sua força criadora $\mathrm{e}$ constitutiva, embora certos "cortes" metodológicos e restrições possam mostrar um quadro estável e constituído. Não há nada de universal, salvo o processo - a forma, a estrutura dessa atividade. A linguagem, pois, não é um dado ou resultado; mas um trabalho que dá forma ao conteúdo de nossas experiências, trabalho de construção, de retificação do "vivido" que ao mesmo tempo constitui o sistema simbólico mediante o qual se opera sobre a realidade e constitui a realidade como um sistema de referências em que aquele se torna significativo (FRANCHI, 1977, p. 22).

Concebemos a linguagem como o resultado do trabalho dos sujeitos na construção de sentidos para os textos e os discursos. A situação histórico-social é o espaço no qual se dão as interações dos sujeitos, sendo toda interação uma 
relação interlocutiva compartilhada, na qual há o trabalho conjunto dos sujeitos e a participação dos sistemas de referência (de cada sujeito) e das formações sociais específicas. Assim, há um movimento constitutivo da linguagem que se dá, na história, pelo trabalho de sujeitos. Não acreditamos na possibilidade de pensar a linguagem sem a mediação que ocorre nas relações interativas.

Um bom exemplo do que pode ocorrer a partir de pontos de vista divergentes acerca de um único fenômeno, implicando distintas análises, é dado pelos estudos linguísticos acerca do erro. Durante um longo tempo o erro foi visto como aquilo que destoa na produção linguística de outra realização tomada como padrão, esta, em geral, proveniente de segmento social prestigiado social, econômica e culturalmente. Estudos e práticas pedagógicas ignoravam o fato de que os erros cometidos pelos aprendizes poderiam ser vistos como preciosos indícios de um processo em curso, da aquisição da linguagem.

Há algumas décadas, a Psicolinguística retirou do chamado erro o estigma que a gramática normativa lhe impusera, promovendo-o a um lugar de destaque entre seus procedimentos metodológicos. A opção pelo exame desse tipo de dado se faz sempre que se olha a aquisição da linguagem na perspectiva de um fenômeno presente no desenvolvimento linguístico, denominado processo de reorganização, e sua importância como indício de construção de subsistemas confere a ele uma posição de proeminência metodológica nessa área de estudos.

A atitude metodológica de valorização do erro repercutiu na postura teórica presente em estudos sobre aquisição da linguagem oral (FIGUEIRA, 1991, 1996; LEMOS, 1982, 1984), inaugurando reinterpretações dos dados por pesquisadores. De acordo com Figueira (1991), inicialmente banido e depois resgatado pelos estudiosos da linguagem, o erro conheceu assim uma trajetória que foi - pode-se dizer - da exclusão discriminada de alguns para o olhar imparcial e atento de outros, que pretendem extrair desse rico material mais do que aquilo que pode ser revelado via sua contraparte normal ou correta.

Lemos (1982, p. 110) dá exemplos de erros cometidos pela criança em fase de aquisição da linguagem que, antes de se revelarem como desviantes, são evidências "de um processo de organização de procedimentos justapostos, ou de coordenação entre esquemas, que levará a criança a operar com subsistemas ou entidades mais abstratas". Segundo a autora, exercendo uma atividade discursiva, a criança estaria revelando um uso comunicativo (ação sobre o outro), um uso cognitivo (ação sobre o mundo) e uma elaboração da linguagem enquanto sistema de regras.

Bowerman (1982) trata do erro enquanto inserido no fenômeno da reorganização e Coudry $(1987,2002)$ entende que "esses fenômenos, erros do ponto de vista da escola, revelam operações epilingüísticas ${ }^{5}$ que ocorrem em

\footnotetext{
${ }^{5}$ Operações epilinguísticas são as que se referem à reflexão sobre a linguagem em uso, tais como os recursos expressivos e a estética, sem preocupação com classificação e nomenclatura, próprias das operações metalinguísticas, muito trabalhadas nas aulas de Gramática (GERALDI, 1993).
} 
momentos em que a criança está operando com a linguagem como um objeto de conhecimento" (1987, p. 154). Ambas as autoras são representantes de um grupo de pensadores que evidenciam um movimento, ocorrido nos estudos linguísticos, de (re)interpretar o erro e considerá-lo enquanto ocorrência tanto pertinente quanto desejável nos processos de aquisição de linguagem.

Ao considerarmos a sua realidade linguística, devemos lembrar que aos 5 ou 6 anos as crianças são capazes de entender e falar a língua portuguesa com desenvoltura, nas mais diversas circunstâncias de suas vidas. Segundo Cagliari (2008), as crianças aprendem a falar e a entender o que lhes falam a partir do primeiro ano de vida, quando se revela a ocorrência do desenvolvimento de um processo de aquisição da linguagem. Um determinado número de fatores concorre para esse desenvolvimento, dos quais Gagné (2002, p. 187) considera como mais importantes: "presença da linguagem no meio ambiente; estímulo e reforço por parte dos adultos; atividades linguísticas numerosas da parte da criança; atividades linguísticas motivadas por necessidades e funções autênticas da criança”.

Aos 3 anos as crianças atingem um ponto que permite considerá-las falantes nativas de uma língua, o que significa dizer que elas dispõem de um vocabulário e de regras gramaticais. De acordo com Cagliari (2008, p. 18), “o vocabulário de uma criança de 3 anos é pequeno e ela é capaz de entender um número maior de palavras do que o que usa", generalizando regras gerais na fala quando deveria aplicar uma particular, o que resulta em elementos como "eu fazi", "eu sabo", "se eu sesse". Gagné (2002) aponta que pesquisas mostraram certa capacidade da criança de se adaptar às características de seu interlocutor, sendo que a eficácia da comunicação das crianças de 5 a 13 anos aumenta também devido à representação das características do interlocutor, que, mesmo para crianças em idade pré-escolar, são consideradas e previstas.

As autoras e autores cujos escritos contribuem para a concepção aqui adotada de linguagem e da caracterização da linguagem infantil sugerem, portanto, que a linguagem se constitui na construção de sentidos pelos sujeitos, em interações situadas histórica e socialmente, que os falantes da língua, aos 5 anos, possuem saberes sobre ela e que seus erros revelam uma lógica própria.

\section{Metodologia}

\section{Metodologia da pesquisa}

Duas orientações metodológicas orientaram a pesquisa: o Paradigma Indiciário e o que podemos considerar uma vertente da pesquisa-ação, para a qual têm contribuído alguns autores brasileiros.

Para Ginzburg (1991, p. 98), a metodologia indiciária tem suas raízes em hábitos milenares da humanidade, tais como o de caçar. Por milhares de anos a humanidade aprendeu "a dar sentido e contexto ao traço mais sutil [e] [...] a realizar maquinações complexas em átimos de segundo”. Para este autor, a metodologia indiciária encontra-se baseada em figuras de linguagem - a parte 
pelo todo, a causa pelo efeito -, na linguagem de decifração de rastros, "relacionando-se com o pólo narrativo da metonímia [...] e excluindo, de modo estrito, o pólo alternativo da metáfora" (GINZBURG, 1991, p. 100). O autor entende que essa "decifração" e "leitura" dos traços animais é metafórica.

O Paradigma Indiciário situa-se no velho debate sobre método-hipotético e método interpretativo, o qual deu margem ao já superado debate entre métodos quantitativos e qualitativos. Esse paradigma encontrou implícita legitimação em diferentes esferas das atividades humanas, como nas formas de se fazer ciência, olaria, carpintaria, marinha, caça, pesca etc. Entre as ciências que utilizam esse modelo epistemológico pode-se destacar a Psicanálise, a Medicina e a História. Tais ciências, indiciárias, conjeturais, se apóiam em sintomas, pistas, detalhes ou lapsos e se caracterizariam como disciplinas essencialmente qualitativas. Como exemplo desse paradigma Ginzburg (1986) cita o trabalho de três grandes "detetives": Giovani Morelli, Sigmund Freud e Sherlock Holmes. Discutindo os modos de fazer ciência das disciplinas que utilizam o Paradigma Indiciário, Ginzburg (1986) observa que:

[...] o grupo de disciplinas que chamamos de indiciárias [...] não entra absolutamente nos critérios de cientificidade deduzíveis do paradigma galileano. Trata-se, de fato, de disciplinas eminentemente qualitativas, que têm por objeto casos, situações e documentos individuais, enquanto individuais, e justamente por isso alcançam resultados que têm uma margem ineliminável de casualidade [...] ninguém aprende o ofício de conhecedor ou de diagnosticador limitando-se a pôr em prática regras preexistentes. Nesse tipo de conhecimento entram em jogo elementos imponderáveis: faro, golpe de vista, intuição (GINZBURG, 1986, p. 156-179).

De acordo com o autor, a ideia que se encontra no cerne do Paradigma Indiciário é que "a realidade é opaca, mas há certos pontos - pistas, sintomas que nos permitem decifrá-la” (GINZBURG, 1986, p. 127).

A utilização do Paradigma Indiciário contribuiu para redefinir a noção de rigor científico. Este passou a ser construído pela relevância dos dados analisados e pelos respectivos resultados das análises, e não mais por comprovações estatísticas ou matemáticas. $O$ que caracteriza o tipo de análise qualitativa inerente ao Paradigma Indiciário é a possibilidade de olhar para a constituição dos sujeitos (singulares) na tentativa de compreender os dados (únicos).

A opção pela pesquisa-ação se colocou como uma orientação metodológica deste estudo não apenas pelo interesse da pesquisadora discente em observar uma prática pedagógica, mas também pela possibilidade de nela intervir e com isso desencadear processos de aprendizagem para as pessoas envolvidas (ela mesma - como educadora e pesquisadora -, as crianças e a monitora), além de contribuir para a produção de novos conhecimentos. Como foi relatado na seção introdutória, foram questões levantadas na prática que originaram o interesse pelo tema da linguagem nas ações de EA e faria todo sentido voltar para a 
prática para compreender melhor como se dá tal entrelaçamento. A opção pela faixa etária da educação infantil se colocou como alternativa pelo acesso já conquistado junto a um centro municipal de educação infantil (doravante CEMEI) numa cidade de pequeno porte do Estado de São Paulo, na qual reside a pesquisadora discente. A vertente escolhida da pesquisa-ação é aquela que considera os frutos tanto da intervenção quanto da pesquisa, sem colocar em segundo plano esta, tal como vem sendo proposta e exercida por vários autores, como Thiollent (2000) e André (1998). Uma das importantes diferenciações indicadas por esses autores exige demarcação clara dos objetivos da ação e da pesquisa. O propósito da pesquisa e os objetivos da intervenção foram estabelecidos a partir de um diagnóstico inicial e do contato com a equipe do CEMEI visando a que as crianças ampliassem e sistematizassem os seus conhecimentos sobre "água", especialmente aqueles envolvendo a relação dos seres vivos, em especial dos seres humanos, com a água.

Houve a preocupação de cumprir com os procedimentos éticos da universidade à qual as pesquisadoras estão vinculadas; assim, todas as pessoas e instituições envolvidas autorizaram a realização da intervenção. No caso das crianças, seus responsáveis assinaram as autorizações.

\section{A intervenção}

A intervenção foi realizada num CEMEI. A discente pesquisadora foi bem recebida na instituição, que se caracteriza por ser um espaço arejado, com árvores frutíferas, um miniparque e campo para jogar bola.

O período da intervenção foi de 3 meses, num total de 15 horas, precedido de outro período, de 55 horas, dedicado à observação das atividades, com um mês de duração. Participaram 13 (treze) crianças entre 5 e 6 anos.

A intervenção foi elaborada considerando-se as várias situações que envolvem a água no cotidiano dos sujeitos. Os subtemas foram: conceito de água, suas finalidades, importância, desperdício, poluição, músicas e profissões relacionadas à água. Apresentamos a seguir uma descrição das principais propostas didáticas da intervenção realizada, detendo-nos nas ações propostas, pois destacaremos as interações e reações das crianças nas análises.

A mediação sobre o conceito de água partiu da pergunta: "O que é água?", seguida da apresentação de diversas figuras e cartazes e do pedido para que as crianças separassem as figuras que remetiam ou não a água. As crianças foram solicitadas a realizar um desenho sobre água. A discente pesquisadora abordou algumas das principais características da água (incolor, inodora e sem gosto, quando destinada ao consumo humano), seus estados físicos e a relação entre a água e as estações do ano (consumo, chuvas e mudanças climáticas ocorridas em cada estação). Leu-se o livro Menino do rio doce, de Ziraldo (1996), que foi manuseado pelas crianças, e foi conduzida uma conversa sobre a história.

Para refletir sobre as finalidades da água para a vida, mostrou-se e discutiu-se o vídeo Chuá Chuágua (s/d) às crianças. Distribuíram-se ainda revistas para que selecionassem figuras ilustrativas das várias formas de utilização da água. Foram 
explicadas as várias formas de utilização da água a fim de que as crianças não tivessem a visão de que esse recurso natural existe para servir somente ao ser humano (ponto de vista antropocêntrico).

Uma exposição sobre o ciclo da água deu início ao tópico sobre a importância da água na natureza, seguida da mostra e debate sobre imagens que expressavam a importância da água, como um bebê no útero da mãe, a seca nordestina, etc.

O tema do desperdício foi conduzido através da proposição e discussão de questões tais como: Vocês acham que a calçada sente sede? Por que a lavamos? Por que há pessoas que a lavam todos os dias? Será que a água que pinga das torneiras poderia saciar a sede de quem não tem água para beber? Perguntou-se se já haviam visto alguém lavar a calçada e se esta "sentia sede", com o objetivo de levantar o questionamento sobre o costumeiro hábito de lavar calçadas. Ordenaram-se as prioridades de uso da água, tais como: 1- saciar a sede/necessidade de água dos seres vivos; 2- alimentação; 3- higiene pessoal; 4consumo industrial.

Mostraram-se figuras, cartazes e vídeos sobre a poluição das águas a fim de promover sensibilização e conhecimento do que se pode fazer para evitar a morte de animais, plantações etc. Abordou-se o tema "reutilização" introduzindo-se uma minioficina com o intuito de confeccionar brinquedos com materiais reutilizados.

Tendo-se em mãos o livro Poluição das águas, de Bonacella, Magossi e Moura (1990), contaram-se às crianças as várias formas de poluição das águas e mostraram-se as figuras. Após a leitura, foi conduzida uma conversa sobre o que havia sido lido.

Canções do vídeo Chuá Chuágua (s/d) foram cantadas com a turma, assim como se abordaram as profissões relacionadas diretamente ao uso da água, como as de bombeiro, encanador, agricultor etc.

O tema higiene foi abordado remetendo-se a situações cotidianas, como o ato de escovar os dentes, tomar banho, lavar as mãos antes das refeições e limpeza da casa.

\section{Resultados e discussão}

Apresentaremos algumas das principais questões feitas às crianças sobre o tema "água" e suas respostas, tentando classificá-las e analisá-las. As questões remetiam aos conteúdos já apresentados na seção anterior.

Iniciamos a intervenção perguntando às crianças o que era água, para que pudessem fazer as primeiras associações e aproximações com o tema, partindo de suas percepções, vivências e conhecimentos sobre o tema, que é tão presente em suas vidas de diferentes maneiras. As respostas obtidas puderam ser classificadas em 4 (quatro) tipos: 1) respostas que consideram a procedência da água (quatro respostas: "Água da torneira”, “Água do cano”, "Água do céu” e Água da chuva"); 2) uma resposta que remete à finitude da água ("A gente bebe e depois acaba tudo"); 3) uma resposta que menciona a utilização da água para o 
consumo de pessoas e animais (“Água de beber”); e 4) uma resposta genérica e vaga ("Água de tudo"), categoria que não permitiu estabelecer relação com as dimensões anteriores ou outras.

As respostas remeteram a alguns dos elementos que pretendíamos sistematizar, como as diferentes procedências da água, a questão de sua finitude, apropriada para o escopo de uma ação de EA, e a necessidade da água para a vida das pessoas e dos demais seres vivos. A discente pesquisadora, depois das respostas, pediu que as crianças desenhassem, com o objetivo de verificar se expressavam no papel o que responderam anteriormente e se expressavam conceitos generalizados ou algo mais específico. No momento em que lhes foi solicitado um desenho individual, demonstraram contentamento, como se o desenho fosse algo que lhes agradasse, como uma "válvula de escape".

Os desenhos apresentaram o que as crianças haviam respondido sobre o que era água, mas nem todos com traços bem definidos, devido à faixa etária em que se encontram e aos seus diferentes níveis de domínio neurocognitivo necessário para a elaboração de desenhos, como apreensão firme do lápis, projeção espacial de uma imagem, noção de dimensão e escala, traço de detalhes. Sol e chuviscos, por exemplo, apresentavam-se com formas bem definidas; os desenhos que apresentaram rio, chuva, torneira com água, água da caixa remeteram a algum aspecto relativo ao conceito de água e foram considerados pertinentes, pois é uma forma de expressar o que é água, embora seja também uma forma de expressar de onde vem a água ou onde ela está armazenada. Em alguns desenhos a água aparecia em segundo plano, vindo atrás de meninas, pipas, borboletas e corações, entre as meninas, principalmente. Houve um desenho constituído por traços aleatórios nas cores roxa e cinza, mas que, segundo a criança, continha um rio e chuva. Consideramos que apenas um desenho não apresentou qualquer característica relacionada à água, sendo constituído por menina, coração e outros objetos que, acreditamos, eram os objetos familiares para a criança (no ato de desenhar, pelo menos).

Detectamos que uma criança aderia à ideia de outra facilmente e sem constrangimentos e que seus desenhos assemelharam-se uns aos outros no que se refere ao conteúdo. Segundo Dominguez (2006), essa semelhança poderia não ser observada caso os desenhos fossem confeccionados individualmente sem contato entre as crianças no ato da elaboração. Ainda de acordo com a autora, nas situações coletivas as crianças interferem nas ZDPs umas das outras, havendo assim interação de linguagem e desenvolvimento da matéria-prima para processos que não ocorreriam individualmente, pois "pensam alto", falando enquanto desenham ou até mesmo enquanto escrevem.

Lembramos que, como já visto, Gagné (2002) aponta que a linguagem da criança é constituída de acordo com o contexto no qual está inserida e de acordo com a imagem que tem de seu interlocutor, o que pôde ser evidenciado por uma situação na qual uma professora do CEMEI (não se referia aos sujeitos com os quais se realizou a intervenção) disse: "Vocês querem fazer silêncio, por obséquio?". Após alguns minutos o silêncio se desfez e uma menina repreendeu um menino, mesmo sem saber que o fez ao dizer: "A tia pediu silêncio, por 
obséquia". Ao buscar a imitação da fala do adulto, a menina alterou o gênero da palavra nova para ela, o que resultou em "obséquia", um tipo de erro bastante frequente na aprendizagem e no desenvolvimento linguístico das crianças ${ }^{6}$.

Numa das atividades, em que a discente pesquisadora apresentou várias figuras de água, pôde-se notar que as crianças associaram água à cor azul, talvez por ser representada nesta cor em imagens encontradas em livros de rios, lagos, chuvas e mares, na TV e em outros tipos de mídia, assim como são azuis os azulejos de piscinas e os galões de água filtrada da instituição em questão. Tratase de caso típico da influência da linguagem visual na construção de conceitos de um indivíduo e deixa evidente como a água está fortemente presente na vida das crianças. Aliás, tal presença se manifestou em várias circunstâncias em que as atividades da intervenção foram interrompidas para que as crianças tomassem água, fossem ao banheiro ou para chamá-las para longe da grade da piscina.

Ainda quanto à coloração da água nas figuras apresentadas, as crianças consideraram que água com algum tipo de coloração não é ideal para consumo, pois "vem bichinho na barriga", relacionando coloração, principalmente escura, à presença de micro-organismos. Assim, para as crianças, a água mais clara é a ideal para se beber. Tal concepção, embora possa ser em parte questionada, pois nem toda água clara é potável (essa questão foi trabalhada com as crianças durante a intervenção), apresenta em princípio uma ideia em consonância com o conhecimento científico, a de que a água deve estar limpa para ser consumida. Resta, para as crianças desta faixa etária, ampliar o conceito do que seria "água limpa" e entender que nem toda água que parece limpa o está realmente, pois podem estar presentes substâncias que não vemos e que sujam ou contaminam a água, como micro-organismos e metais pesados.

As crianças responderam prontamente às perguntas quando lhes foram mostradas figuras elucidativas que elas conheciam, revelando reação positiva à linguagem visual. Diante da figura de uma piscina, houve comentários mais próximos dos conhecimentos científicos, já apresentados às crianças, como "água não tem cor, não tem cheiro", e comentários que ainda afirmavam que a cor da água era azul. Houve ainda afirmativas em que o novo conhecimento entrava em contradição com os conhecimentos espontâneos: "Tia, então por que a água do mar é daquela cor?".

A pesquisadora explicou que não é a água que é daquela cor, que o fundo do mar, a areia e o reflexo do azul do céu nos dão a impressão de que a água é daquela cor. Diante das primeiras expectativas, de que teriam aprendido que a água era incolor, a discente pesquisadora se deu conta de que o processo de aprendizagem de conceitos ocorre não pela exposição da educadora, mas em um processo contínuo, de retorno ao conforto do conhecimento espontâneo, quando o conhecimento científico ainda não consegue dar respostas satisfatórias,

${ }^{6}$ Importantes referências para o aprofundamento do saber sobre o processo de aquisição da linguagem pelas crianças são os estudos de Rosa Attié Figueira (1991, 1996), na modalidade oral, e Maria Bernadete M. Abaurre et al. (1997) e Roxane Rojo (1994), na modalidade escrita. 
prevalecendo, então, a percepção imediata do fenômeno. O processo conduzido pela instrução, neste caso, buscou criar, segundo Vygotsky (1987), uma ZDP, talvez ainda não alcançada (ou identificada) no momento, marcado ainda pela percepção mais imediata.

Para introduzir a questão de que a água pode ser encontrada sob diferentes formas no ambiente, foi feita a pergunta "O gelo é água?", à qual a maioria respondeu que sim, já que "derrete e vira água", segundo a verbalização de uma das crianças. Assim, para as crianças o gelo é água porque ao derreter assume a forma líquida, com a qual elas têm contato estreito cotidianamente. Vemos que a fala "derrete e vira água" revela um tipo de pensamento que considera a conservação (na acepção piagetiana) da substância água, qualquer que seja o seu estado, sólido ou líquido. Para que esse tipo de pensamento ocorresse, essa criança demonstrou uma capacidade de reversibilidade, que implica em "executar uma mesma ação nos dois sentidos de percurso, mas tendo consciência de que se trata da mesma ação" (BATTRO, 1978, p. 215). Tal capacidade serve como indício de uma estrutura operatória característica do período das operações concretas, no qual já conquistam estruturas lógicas que não sofrerão alterações, posto que já são próprias da lógica formal (PIAGET; INHELDER, 1989).

Outro aspecto a ser comentado sobre essa fala é que, mesmo sem saber nomear tais estados ou dizer que se trata de mudança de estado da água, a criança conseguiu realizar a operação lógica ao identificar que é água, mesmo sendo gelo. Piaget e Inhelder (1989) e Vygotsky (1987) concordam com essa ordem do processo de formação de conceitos, em que muitas vezes uma pessoa sabe operar com o conceito, mas não consegue nomeá-lo ou defini-lo. Um exemplo disso é que muitos de nós conseguimos identificar ruas paralelas, mas poucos somos capazes de elaborar uma definição do conceito de paralelismo em acordo com os conhecimentos atualizados da Geometria. Esse processo de primeiro formar o conceito e depois nomeá-lo é próprio do desenvolvimento humano. Vygotsky (1987) sugere que a linguagem, via mediações (em particular as escolares), ocupa um papel determinante ao direcionar o ensino para compreensões mais organizadas, em que as generalizações são possíveis e os conceitos se reorganizam em níveis mais elaborados. Afirma ainda que na escola muitas vezes o ensino começa com definições (isso ocorre mais a partir do segundo segmento do Ensino Fundamental), o que é também um caminho possível para as aprendizagens. Não sabemos se todas as crianças da turma observada constatariam a conservação da substância água nos dois estados mencionados, sólido e líquido, pois não investigamos.

Reações diferentes se apresentaram frente à pergunta: “A neve é água?”, pois obtivemos respostas "sim" e "não". Uma criança explicou àquelas que disseram "não" que, “quando a neve derrete, vira água. Então, neve é água”. Mas, ao que tudo indica, o desconhecimento da neve, distante da realidade dessas crianças, comprometeu o entendimento de que a mudança de estado não significa mudança de substância.

Uma constatação que gostaríamos de registrar diz respeito aos limites da compreensão pelas crianças de metáforas empregadas no livro Menino do rio 
doce, de Ziraldo (1996). Nessa obra o autor escreve: "O menino aprendeu que a água - em gotas - da chuva era a refeição do rio e que quando chove muito eis que o rio engorda e engrossa e, guloso, engole a margem e vai levando a cerca e vai comendo a casa e vai tragando a árvore..." (s/p). Ao afirmar que a chuva é refeição do rio, o autor emprega uma metáfora para a ideia de que são as águas das chuvas que formam o rio, o que é uma aproximação bastante correta do conceito científico de rio como um canal de drenagem de superfície, de acordo com Art (1998). Entretanto, a ideia vem junto a outra, de que nas enchentes o rio pode trazer para o seu leito outros objetos, alheios a sua formação, como a árvore, a cerca e a casa. Ao buscar verificar a compreensão que as crianças haviam tido sobre a formação do rio, a discente pesquisadora perguntou usando a linguagem metafórica do livro: "Do que o rio se alimenta?". As respostas das crianças evidenciaram que não conseguiram separar o que eram os elementos próprios da constituição do rio (água, nesse caso, da chuva) dos alheios a ela (cerca, casa e árvore): "De criança"; "De casa"; "De cobra"; "De gente"; "De galinha"; "De água"; "De chuva".

Talvez a reformulação da questão numa linguagem mais próxima à científica pudesse ter ajudado as crianças a não interpretarem a questão ao pé da letra e separarem os elementos mencionados. A compreensão dessas ideias foi mais bem explorada quando a discente pesquisadora perguntou: "E o que vocês acham que significa quando dizemos que o rio engoliu cerca, casa, árvore?”, cujas respostas podem ser reunidas em somente uma: "Ele comeu o menino".

Em seguida, a discente pesquisadora perguntou-lhes se o rio tinha boca e a resposta foi unânime e afirmativa. "Mas é uma boca igual à nossa, com dentes e língua?", insistiu a discente pesquisadora. As respostas obtidas correspondem a uma quantidade significativa dos sujeitos: "É"; "E é bem grande"; "O rio tem olho"; "Tem nariz"; "Tem cabeça”.

Nesse momento, a discente pesquisadora pediu a eles que observassem a figura que ilustra a capa do livro, que é um rio. Foi-lhes perguntado se viam uma boca na figura e a resposta foi afirmativa pela maioria. Então, foi pedido que apontassem para a boca do rio. Uma criança apontou para os traços do desenho que representavam as ondas. Assim, percebemos que houve interpretação literal dessa metáfora pelas crianças.

Segundo pesquisas já realizadas, esse é um tipo de metáfora primária que utiliza uma associação com os elementos do corpo humano. É entendido mais precocemente do que as metáforas complexas, que não fazem tal associação e dependem do conhecimento contextual e do entendimento da intenção do interlocutor. Estudos realizados (como o de SIQUEIRA; LAMPRECHT, 2007, e outros por elas citados) apontam que já seria possível para as crianças dessa faixa etária compreenderem esse tipo de metáfora (como indica a última resposta de uma das crianças, de que o rio se alimenta de chuva), mas sua utilização teria de ser objeto de um ensino sistematizado.

Outro fenômeno em jogo nessa questão sobre as metáforas de Menino do rio doce é o animismo, ou seja, a atribuição de capacidades ou feições humanas a animais, plantas ou seres inanimados (PIAGET, 1973). O autor do livro lido para 
a turma recorreu a esse fenômeno, como fazem inúmeros escritores de livros infantis. A nossa compreensão é que o animismo não deve ser combatido na prática educativa na educação infantil, mas a diferença entre o real e o fantástico deve ser estabelecida, questionada, apontada, para que aos poucos possa ser compreendida pelos estudantes, quanto ao conteúdo e ao recurso estilístico. $\mathrm{O}$ questionamento feito pela discente pesquisadora, diante de sua surpresa com a não compreensão das crianças de que o rio não tinha boca, nariz, olho ou cabeça, ilustra uma possibilidade de interação no sentido dessa diferenciação.

Retornando aos dados coletados, num determinado momento da intervenção tratou-se da água que existe no corpo humano, ainda se enquadrando na questão da importância da água. Frente à pergunta: "Como a água que está no nosso corpo sai?”, (as crianças já haviam dito que no corpo humano há água), unanimemente, não houve resposta, talvez pelo modo como a pergunta foi formulada. Então, houve reelaboração da pergunta, remetendo a uma das formas de eliminação da água do organismo: "Quando a gente corre muito, o que acontece?". As respostas podem ser resumidas em: 1) uma que remete à consequência do que ocorre após uma corrida, expressa por várias crianças ("Fica suado") e 2) conseqüência de brincadeiras nas quais se perde água e sais minerais em forma de suor ("Porque sente sede"). Foram, portanto, respostas pertinentes à pergunta.

Quando se trabalhou com a questão do desperdício, detectou-se que as crianças já possuíam uma bagagem de conhecimento sobre o tema, pois, após o início desse assunto e frente à pergunta: "O que a gente pode fazer para não desperdiçar água?", as respostas foram pertinentes e de acordo com o que geralmente é ensinado na escola: "Tomar tudo, tia" e "Quem tá com sede bebe água". A primeira resposta apresenta uma lógica mais diretamente relacionada à pergunta feita, ao passo que a lógica da segunda resposta parece ser que consumindo apenas o necessário se pode evitar o desperdício. A ideia de consumir apenas o necessário é crucial para qualquer ação de EA e está no centro do conceito de desenvolvimento sustentável apresentado no Relatório Bruntland, que é referência para a elaboração posterior do conceito de sustentabilidade e sociedades sustentáveis:

O desenvolvimento sustentável é aquele que atende às necessidades do presente sem comprometer a possibilidade de as gerações futuras atenderem as suas próprias necessidades. Ele contém dois conceitos-chave: o conceito de "necessidades", sobretudo as necessidades essenciais dos pobres do mundo, que devem receber a máxima prioridade; a noção das limitações que o estágio da tecnologia e da organização social impõe ao meio ambiente, impedindo-o de atender às necessidades presentes e futuras (COMISSÃO..., 1991, p. 46).

Uma das controvérsias mais comuns nas ações e teorizações da EA é relativa ao que cada pessoa entende como necessário, pois as perspectivas serão diversas, conforme sua classe social, seus valores e conhecimentos. As respostas dessas 
crianças, entretanto, parecem não evidenciar dúvidas quanto a como não desperdiçar água. Acreditamos que tais respostas são fruto do trabalho realizado, mas, especialmente, da forma como as refeições são organizadas no CEMEI: as crianças se servem (o que lhes propicia a autonomia na ação tão cotidiana que é se alimentar) e são orientadas pelas monitoras a pegarem somente um pouquinho para não sobrar e porque quem quiser comer mais bastará se levantar e se servir. A mesma orientação é dada quando sentem sede, pois as crianças sabem que não se deve desperdiçar e expressam as orientações que lhes foram dadas, como: "Escovar dente com a torneira fechada"; "Desligar o chuveiro" (inferimos que seja desligar o chuveiro enquanto se ensaboa); "Não deixar a torneira aberta, tia" (nesse caso, também se infere que não se deve deixar a torneira aberta enquanto se faz outra coisa); "Não pode largar o filtro aberto".

Dando continuidade ao tema do desperdício da água, a pesquisadora remeteu à questão da lavagem das calçadas. Quando lhes foi perguntado se já haviam visto alguém lavando a calçada, a resposta foi afirmativa, em coro, e, quando lhes foi perguntado se achavam que a calçada sentia sede, a resposta da maioria foi afirmativa. Provavelmente, essa afirmação ocorreu em virtude da não compreensão dessa metáfora, como já discutimos anteriormente. Conseguimos identificar três tipos de respostas das crianças, dois dos quais não contestam a ação, enquanto o terceiro tipo responde negativamente à pergunta sobre a sede da calçada. O primeiro tipo fazia associações entre o termo "sede", da pergunta, ora com a sede de quem lava a calçada, ora com a das plantas, provavelmente porque sua rega deve ser feita no mesmo momento em que o adulto lava a calçada, ou porque há plantas na calçada, como nas afirmativas: "Porque quem lava fica no sol" e "A planta sente sede". O segundo tipo de respostas expõe o modo como se faz para limpar a calçada, explicitando naquele momento ser a melhor forma: "A mãe joga água da torneira" e "A gente pega a torneira e lava". E o terceiro tipo, como anunciamos, nega a sede da calçada: "Ela não pede água". Aberta a possibilidade de uma perspectiva mais crítica com esta última resposta, indagou-se às crianças o porquê de se lavar a calçada, para que as concepções sobre esse hábito pudessem vir à tona e ser problematizadas.

A primeira resposta correspondeu à justificativa usual das pessoas para lavarem suas calçadas, embora sem considerar alternativas à lavagem: "O vento vem, derruba as folhas e suja". Tal justificativa pode ser compreendida como um dos argumentos utilizados nos ambientes familiares para se lavar a calçada com água, uma ação que muitos autores de EA recomendam que seja substituída pela varredura, que é mais sustentável. Outra resposta, provavelmente resultado da associação ou lembrança de alguma experiência da criança ao observar uma calçada ser lavada: "Porque sai sapo". A resposta de uma terceira criança foi: "A nuvem tem chuva", afirmativa que pareceu assumir que a chuva produzida na nuvem poderia ser empregada para a limpeza das calçadas, alternativa que seria contrária à limpeza com água e que não considerou a alternativa da varrição, posto que quando não chove as pessoas costumam continuar querendo suas calçadas limpas. Aproveitando essa resposta, a intervenção seguiu dando continuidade a esse tema da limpeza das calçadas. 
Perguntou-se às crianças se quando chovia a calçada era lavada. A primeira resposta foi afirmativa e direta: "Lava", seguida por outra resposta possivelmente contrária à limpeza por meio da chuva, pois colocou um problema para a lavagem da calçada pela chuva: "Se chover, vai escorregar na água", ideia à qual se contrapôs outra criança, que corrigiu afirmando que "Escorrega com detergente". A última resposta remeteu à varredura, presumimos que como forma mais eficaz de limpeza: "Pra varrer".

A pesquisadora discente manteve o tema e perguntou se havia pessoas que lavavam a calçada todos os dias, obtendo respostas negativas ("Não") e com a alternativa da varredura: "Só varre". Após um elogio e confirmação de que primeiro se deve varrer e, se necessário, lavar a calçada, uma criança expressou o que provavelmente ocorre em sua casa ou ambiente de maior convívio familiar: "Lava um dia sim e outro não. No sim e outro, não, tia".

Um dos temas abordados na intervenção foi o da poluição, que teve início com a pergunta: "O que é poluição?", para a qual houve dois grupos de respostas, as que estabeleciam uma relação de pertinência com poluição e as que se distanciavam desse conceito. No primeiro grupo, com prevalência da maior parte da turma, algumas das respostas foram: "Água"; "Fumaça"; "Avião que solta óleo"; "Esgoto”; "Xixi, cocô”; “Água fedida”; “Água da dengue”; “Água da chuva" e "Cozinha da água". E no segundo grupo houve as respostas "Sol" e "Chuveiro". De maneira geral, as primeiras respostas podem ser consideradas positivas, embora as crianças não tenham respondido exatamente o que se esperava, o que revela, mais uma vez, a importância de se atentar para a linguagem quando se trabalha com crianças nessa faixa etária, para que compreendam a diferença entre "O que é?" e "Como é?".

Como últimas observações gerais sobre a questão da linguagem nas atividades desenvolvidas, indicamos algumas anotações. A pesquisadora discente notou que era comum as crianças se referirem a algo como "aquela coisa" ou "esse negócio", não mencionando, muitas vezes, o nome do objeto. De modo geral, as crianças utilizaram palavras e termos gerais (como "água para beber" em resposta ao que é água e para que serve) para responder às perguntas relacionadas ao tema "água", o que provavelmente também ocorreria se houvesse seleção de outra temática. Assim, fica evidente a importância em ter cuidado (e conhecimento do funcionamento da linguagem utilizada pela criança) no uso das palavras e no modo como uma aula é conduzida, o que remete à recomendação de prever ações educativas que tenham por objetivo o emprego de termos específicos e o questionamento do uso de termos genéricos como os mencionados, levantando-se alternativas de uso da linguagem que busquem torná-la mais precisa, a serviço de uma comunicação efetiva, e possibilitem níveis de conceitualização mais abrangentes.

As crianças foram extremamente espontâneas ao expressarem o que achavam das atividades. Algumas, se não gostavam e para chamarem a atenção para si de alguma forma, diziam imediatamente: "É muito chato ficar falando de água. Eu já sei tudo. Água é boa pra gente beber e pronto". Parece que é comum entre educandos de diferentes faixas etárias a queixa de mesmice quando se 
escolhe um tema para ser aprofundado, como foi o caso nessa intervenção e parece ser o caso quando se organiza o trabalho escolar por projetos. Essa queixa representa um desafio para os educadores que acreditam na organização do trabalho educativo por projetos, nos quais buscamos tanto um aprofundamento dos temas quanto aproximações e diálogos entre diferentes áreas do conhecimento.

\section{Conclusões}

É muito comum ouvirmos a crença de que as ações de EA deveriam se voltar para as crianças, consideradas a grande esperança para a mudança de atitudes, possivelmente em contraponto aos adultos, que não teriam tal potencial. Entretanto, os educadores que se dedicam à educação infantil sabem que não é tão simples conduzir ações educativas com crianças pequenas, seja sobre a temática ambiental, seja sobre outras, por distintas razões, algumas das quais se fizeram notar neste trabalho. Escolhemos, entre os dados coletados, voltar o olhar para o encontro entre a linguagem e a EA e é a esse encontro que dedicaremos estas considerações finais.

Conduzir uma ação educativa em torno da temática ambiental com crianças pequenas, como na faixa etária dos 5 anos, requer a consideração de vários aspectos linguísticos se a preocupação central é a comunicação efetiva entre educadores e crianças. As falas das crianças que aqui analisamos remetem a características peculiares, relativas às situações de comunicação criadas pela intervenção sobre água, assim como a diferentes aspectos do contexto educativo em questão.

Assinalaremos a seguir algumas observações resultantes das análises dos dados, apresentadas na seção anterior, buscando indicar reflexões, questionamentos e, por vezes, orientações possíveis para a ação educativa, com base em três tópicos principais, que destacamos das análises: linguagem e formação de conceitos; compreensão e uso de metáforas e outras imagens; e linguagem e a dimensão dos valores na EA.

A linguagem das crianças revelou alguns aspectos sobre a formação de conceitos, em particular sobre as suas formas de pensar, ou seja, suas lógicas, ainda muito marcadas pelas percepções imediatas, como pudemos constatar nas respostas sobre a cor da água e nas opiniões divergentes sobre se a neve é água.

Uma das contribuições para a reflexão sobre a linguagem e a EA na educação infantil desta pesquisa se refere ao levantamento sobre a compreensão de metáforas, especialmente as que remetem a características humanas, muito empregadas nas imagens (criadas pela escrita ou nos desenhos) sobre as diferentes questões ambientais. Ainda há muito a investigar para que se derivem reflexões que revertam em melhorias das ações educativas. Quais orientações podemos pensar para a condução da ação educativa quanto à diferenciação entre realidade e fantasia? Qual é a compreensão, ao longo das faixas etárias, dos diferentes tipos de metáforas usualmente empregados na EA? A discussão de 
imagens, como proposta por Reigota (1999), poderia se constituir num caminho profícuo para a EA nessa faixa etária?

As mediações em torno do tema do desperdício, tão caro aos educadores ambientais, também nos deixam indagações quanto ao trabalho com crianças. É um tema permeado de valores éticos e passível de múltiplas perspectivas e muitas problematizações. Como alguns autores já indicaram em outros trabalhos, embora a dimensão dos conhecimentos seja fundamental, ela não é suficiente para pautar ações e pesquisas de EA, pois entram em jogo, para formar o sujeito ecológico, dimensões relativas aos valores éticos e estéticos e à participação política (CARVALHO et al., 1996). No caso desta pesquisa pudemos notar que os diálogos sobre o desperdício se apresentaram muito ricos de posicionamentos, que, por sua vez, levaram a intervenções de outras crianças e da pesquisadora discente, que pôde destacar diferentes aspectos relativos ao desperdício da água: o que entendiam por desperdício, se achavam que limpar a calçada com água era a melhor solução, as razões das pessoas para lavarem a calçada, o que era ou não necessário e se achavam que a chuva poderia exercer a função de limpeza da calçada.

\section{Referências}

ABAURRE, M. B.; FIAD, R. S.; MAYRINK-SABINSON, M. L. Cenas de aquisição da escrita. São Paulo: Mercado de Letras. 1997.

ANDRÉ, M. E. A. Desafios da pesquisa sobre a prática pedagógica. In: ENCONTRO NACIONAL DE DIDÁTICA E PRÁTICA DE ENSINO, 9., 1998, Águas de Lindoia. Anais... São Paulo: FEUSP, 1998. p. 257-266.

ART, H. W. Dicionário de Ecologia e Ciências Ambientais. São Paulo: Unesp; Cia. Melhoramentos, 1998.

BATTRO, A. Dicionário Terminológico de Jean Piaget. São Paulo: Pioneira, 1978.

BONACELlA, P. H.; MAGOSSI, L. R.; MOURA L. Poluição das águas. São Paulo: Moderna. 1990.

BOWERMAN, M. Re-organizational processes im lexical and syntactic development. In: WANNER, E.; GLEITMAN, I. (Ed.). Language acquisition: the state of the art. Cambridge: Cambridge University Press, 1982. p. 320-346.

BRASIL. Ministério da Educação e do Desporto. Secretaria de Educação Fundamental. Referencial curricular nacional para educação infantil. Brasília: MEC/SEF, 1998.

CAGLIARI, L. C. Alfabetização \& Linguística. 10. ed. São Paulo: Scipione, 2008.

CARVALHO, I. C. de M. Atitude, comportamento e ação política: elementos para pensar a formação ecológica. In: . Educaşão ambiental: a formação do sujeito ecológico. São Paulo: Cortez, 2004. p.175-191. 
CARVALHO, L. M. de et al. Conceitos, valores e participação política. In: TRAJBER, R.; MANZOCHI, L. (Org.). Avaliando a Educação Ambiental no Brasil: materiais impressos. São Paulo: Gaia, 1996. p. 77-119.

CHUA CHUÁ. Produção de Sônia Coutinho. Direção de Cristina Winther e Roseli Ferro. Realização: CETESB e TV Cultura. São Paulo, s/d, 1 VHS.

COMISSÃO MUNDIAL SOBRE MEIO AMBIENTE E DESENVOLVIMENTO. Nosso futuro comum. Rio de Janeiro: Fundação Getúlio Vargas, 1991.

COUDRY, M. I. H. Dislexia: um bem necessário. Estudos Lingüísticos, Campinas, SP, v. 1, p. $150-157,1987$.

. Linguagem e afasia: uma abordagem discursiva da neurolingüística. Cadernos de Estudos Lingüisticos, Campinas, SP, n. 42, p. 99-129, 2002.

DOMINGUEZ, C. R. C. Palavras e imagens: acesso ao mundo. In: Desenhos, palavras e borboletas na educação infantil: brincadeiras com as idéias no processo de significação sobre os seres vivos. 2006. 174 f. Tese (Doutorado em Educação) Faculdade de Educação, Universidade de São Paulo, São Paulo, 2006.

FIGUEIRA, R. A. O erro como dado de eleição nos estudos de aquisição da escrita. Apresentado no I GRUPO DE TRABALHO SOBRE LETRAMENTO, ALFABETIZAÇÃO E DESENVOLVIMENTO DA LINGUAGEM ESCRITA. PUCSP (mimeo), 1991.

O erro como dado de eleição nos estudos de aquisição da linguagem. In: CASTRO, M. F. P. (Org.). O método e o dado nos estudos da Linguagem. Campinas, SP: Unicamp, 1996.

FRANCHI, C. Linguagem - atividade constitutiva. In: Almanaque 5. São Paulo: Brasiliense, 1977.

GAGNE, G. A norma e o ensino da língua materna. Tradução de Marcos Bagno. In: BAGNO, M.; GILLES, G.; STUBBS, M. Lingua Materna: letramento, variação \& ensino. 2. ed. São Paulo: Parábola, 2002.

GERALDI, J. W. Portos de passagem. São Paulo: Martins Fontes, 1993.

GINZBURG, C. Mitos, emblemas e sinais: morfologia e história. São Paulo: Companhia das Letras. 1986.

. Chaves do mistério: Morelli, Freud e Sherlock Holmes. In: ECO, U.; SEBEOK, T. A. (Org.). O signo de três. Tradução de Silvana Garcia. São Paulo: Perspectiva, 1991. (Col. Estudos 121).

KAWASAKI, C. S. et al. A pesquisa em educação ambiental nos EPEAs (2001-2007): natureza dos trabalhos, contextos educacionais e focos temáticos. Revista Pesquisa em Educação Ambiental, v. 4, n. 2, p. 147-163, 2009. Disponível em: <http://www.epea.tmp.br/revnant42sum.html. Acesso em 06 out. 2010.

LEMOS C. T. G. de. Sobre aquisição da linguagem e seu dilema (pecado) original. Boletim da Abralin, n. 3, p. 97-126, 1982. 
Teorias da diferença e teorias do déficit: reflexões sobre programas de intervenção na pré-escola e na alfabetização. SEMINÁRIO MULTIDISCIPLINAR DE ALFABETIZAÇÃO, 1983, São Paulo. Anais... Brasília: INEP, 1984. p. 133-145.

PIAGET, J. Seis estudos de Psicologia. 6. ed. Rio de Janeiro: Forense-Universitária, 1973.

PIAGET, J.; INHELDER, B. A Psicologia da criança. Rio de Janeiro: Bertrand Brasil, 1989.

REIGOTA, M. A escola e a floresta. São Paulo: Cortez, 1999.

ROJO, R. A noção de fala letrada: implicações psicolingüísticas. Estudos Linguísticos, v. XVII Anais de Seminário do GEL, Ribeirão Preto, 1992. 1994, v. I, p. 51-58.

RUFFINO, S. F. A Educação ambiental nas escolas municipais de educação infantil de São CarlosSP. 2003. 117 f. Dissertação (Mestrado em Educação) - Centro de Educação e Ciências Humanas, Universidade Federal de São Carlos, São Carlos, 2003.

SIQUEIRA, M.; LAMPRECHT, R. R. As metáforas primárias na aquisição da linguagem: um estudo interlinguístico. Delta, v. 23, n. 2, p. 245-272, 2007.

THIOLLENT, M. Metodologia da Pesquisa-ação. São Paulo: Cortez, Editores Associados, 2000.

VYGOTSKY, L. S. Pensamento e linguagem. São Paulo: Martins Fontes, 1987. . A formação social da mente. São Paulo: Martins Fontes, 1988.

ZABALA, A. A prática educativa: como ensinar. Porto Alegre: Artmed, 2008.

ZIRALDO. Menino do rio doce. São Paulo: Companhia das Letrinhas, 1996.

Artigo recebido em 14/10/2011 e aprovado em 12/7/2011. 